\title{
Medicine and Manipulation: Aspiration and Ambition
}

\author{
"And so, light your face up with a smile, \\ Why waste your life on something really not worthwhile, \\ Look up to the stars, take your eyes off the ground, \\ Come, live your life, turn around."1
}

As Doctors of Medicine we should be no strangers to aspiration;"a striving after something higher than oneself" that "usually implies that the striver is thereby ennobled."2 Aspiration in this context truly earns us the full connotation of the title "Doctor," as eminent, authoritative, learned healers and teachers of the art and science of medicine. Many among us deserve this title in word and deed, and are worthy of emulation. Their personal and professional lives bear witness, not to self-serving accomplishments, but to their improving life and living in the world around them.

Aspiration may be synonymous with ambition, although the latter term which"applies to the desire for personal advancement"may equally suggest "a praiseworthy or an inordinate desire ... for rank, fame or power." ${ }^{2}$ Ambition of this sort often resorts to manipulation to achieve its ends, and manipulation in this context is "to control or play upon by artful, unfair, or insidious means especially to one's own advantage." ${ }^{3}$ Whether subtly stolen or brazenly grabbed at the expense of others, the means is often distorted to justify the end. In the process, rights are trampled, dreams shattered, alliances betrayed and relationships severed. According to Messina and Messina ${ }^{4}$, manipulation is a set of behaviors whose goal is to:

- Get you what you want from others even when the others are not willing initially to give it to you.

- Make it seem to others that they have come up with an idea or offer of help on their own when in reality you have worked on them to promote this idea or need for help for your own benefit.

- Dishonestly get people to do or act in a way which they might not have freely chosen on their own.
- $\quad$ "Con" people to believe what you want them to believe as true.

- Get "your way" in almost every interaction you have with people, places, or things.

- Present reality the way you want others to see it rather than the way it "really is."

- Hide behind a "mask" and let people see you in an acceptable way when in reality you are actually feeling or acting in an "unacceptable" way for these people.

- Maintain control and power over others even though they think they have the control and power.

Manipulation also means "to change by artful or unfair means so as to serve one's purpose" or, shameful as it may sound, to "doctor." This derogatory use of the term is not untainted by our actions, whether the arena be laboratory or operating theatre, clinic or lecture hall, hospital or home, interest group or organization, community or society. Blind ambition may delude us into rationalizing dodgy deals and shady maneuverings, convincing even ourselves that they are beneficent and non-maleficent. We get our way, oblivious to the injustice and injury wrought on others. When shameless machinations, "scheming, crafty actions or artful designs intended to accomplish some usually evil end" ${ }^{\prime \prime}$ are engaged in by supposed practitioners of the healing art, they do more than validate the colloquial dinu-doktor or dinuktor; they invalidate the rest of us. 